\title{
Different Types of PWM Techniques analysis for Z-Source Inverter
}

\author{
Sangeeta DebBarman ${ }^{1}$, Tapas Roy ${ }^{2}$ \\ ${ }^{1}$ (M.TECH (Power Electronics \& Drives), School of Electrical Engineering, KIIT University, Odhisa,India) \\ ${ }^{2}$ (Assistant Professor, School of Electrical Engineering, KIIT University, Odhisa, India)
}

\begin{abstract}
This paper presents a recent popular power inverter which is impedance source or Z-source inverter (ZSI) and the comparison and analysis of two conventional PWM techniques of Z-source inverter. Due to the impedance network it couples inverter main circuit to the power source thus providing special features that can overcome the limitations of traditional voltage source inverter (VSI) and current source inverter(CSI).In this paper we discussed and analyzed about the different conventional PWM techniques like Simple Boost Control, Maximum Boost Control, Maximum Boost Control with third harmonic injection, Maximum Boost Control with triplen injection where it is observed that the Maximum Boost Control with triplen injection is much better than other techniques in respect of load current ripple, inductor current ripple and capacitor voltage ripple for different modulation index and same switching frequency.
\end{abstract}

Keywords: Z-source inverter; PWM techniques.

\section{Introduction}

The limitation of VSI (Voltage source inverter) is that the ac output voltage cannot be more than the dc bus voltage. Similarly for CSI (Current source inverter), the output ac voltage has to be greater than the original $\mathrm{dc}$ voltage that feeds the dc inductor, dc voltage produced is always smaller than the ac input voltage That means the VSI is a buck inverter whereas CSI is a boost inverter. On the other hand in case of these two inverters, the upper and lower devices of each phase leg cannot be turn on simultaneously either by purpose or by EMI noise. If a shoot-through state occurs then these inverters get damaged. There we need to provide dead time in between upper and lower gate pulses for each leg. To avoid these limitations of VSI \& CSI, Z-source inverter is introduced in 2003[2].Z-source inverter is much reliable buck-boost capable inverter with impedance network. Z-source inverter is a very recently used inverter. Generally in traditional inverter there are various conventional PWM techniques like Sine triangle PWM, Space Vector PWM techniques. Likewise in Z-source inverter there are various types of conventional PWM techniques used to control Z-source inverter. These techniques are Simple Boost Control (SBC), Maximum Boost Control (MBC) Maximum Boost Control with third harmonic injection, Maximum Boost Control with triplen injection will be analyzed and compared through simulation by MATLAB.

\section{Z-Source Inverter}

The equivalent circuit of the impedance network is shown below fig 1 . For simplicity, assuming that the inductors $\mathrm{L}_{1}$ and $\mathrm{L}_{2}$ and capacitors $\mathrm{C}_{1}$ and $\mathrm{C}_{2}$ in the figure have the same inductance and capacitance respectively, the Z-source network become symmetrical [2].

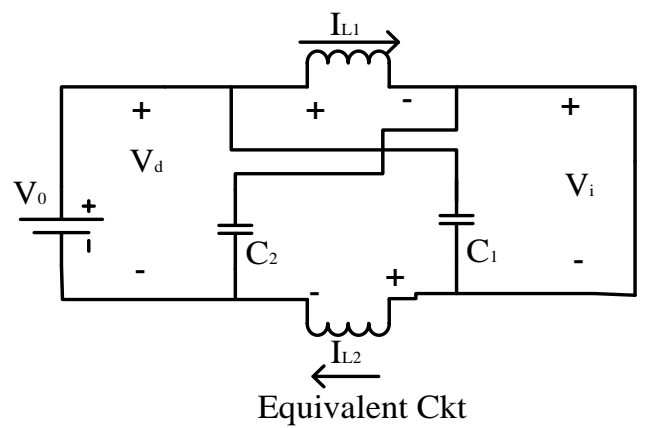

Fig 1 : Equivalent Circuit of Impedance Network 
$\mathrm{B}$ is the boost factor of the inverter which is given by

$$
\begin{aligned}
B & =\frac{T}{T_{1}-T_{0}}=\frac{1}{\frac{T_{1}-T_{0}}{T}}=\frac{1}{\frac{T_{1}-T_{0}-T_{0}}{T}} \\
& =\frac{1}{1-2 \frac{T_{0}}{T}}
\end{aligned}
$$

$\mathrm{T}_{1}$ is the non-shoot through time, $\mathrm{T}_{0}$ is the shoot through time, $\mathrm{T}$ is the switching period Output peak phase voltage obtained from inverter is expressed as

$\mathrm{V}_{\text {out }}=\mathrm{M}^{*} \mathrm{~V}_{0} / 2$

$\mathrm{V}_{\mathrm{ac}}=\mathrm{M} \cdot \mathrm{B} \cdot \mathrm{V}_{0} / 2$

Where $\mathrm{M}$ is the modulation index

The boost factor B is determined by the modulation index $\mathrm{M}$.

\section{Simple Boost Control}

In this method three modulating signals ( $\mathrm{mR}$ for R-phase, $\mathrm{mY}$ for $\mathrm{Y}$-phase, $\mathrm{mB}$ for B-phase) with 120 degree phase shift when compared with high frequency carrier triangular signal it generates switching pulse[7][5]. The shoot-through for Z-source inverter is generated by comparing two straight dc lines with the carrier signal. The magnitudes of these dc lines are $+\mathrm{V}_{\mathrm{sh}}$ and $-\mathrm{V}_{\mathrm{sh}}$ are shown in the figure 2 . When the carrier signal is greater than $+\mathrm{V}_{\mathrm{sh}}$ and less than $-\mathrm{V}_{\mathrm{sh}}$ it will generate shoot-through pulses. If the time duration for shoot-through is $\mathrm{T}_{0}$ and the carrier period $\mathrm{T}$ then shoot-through duty ratio $D_{s h}=T_{0} / T$. Now actual switching pulses for Z-source inverter are then OR between conventional switching pulses shown in figure below to produce the modified pulses $\left(\mathrm{S}_{1}, \mathrm{~S}_{3}, \mathrm{~S}_{5}\right)$ and the invert pulses $\left(\mathrm{S}_{2}, \mathrm{~S}_{4}, \mathrm{~S}_{6}\right)$.In the figure 2, the shoot-through region is shown by hatch line. During the shootthrough all the switches are $\mathrm{ON}$, so here shoot-through state is $\mathrm{V}_{\text {sh15. }}$.

The advantage of this PWM technique is that it is simple to implement but the disadvantage is that total zero switching state is not utilized during shoot-through so the voltage stress across switch is more compared to other techniques. As all the switches turn ON during the shoot-through switching loss is more.

Shoot- through pulses are inserted into the switching waveforms by logical OR gate. For this control method the obtained shoot-through duty ratio decreases with the increase of $\mathrm{M}$.

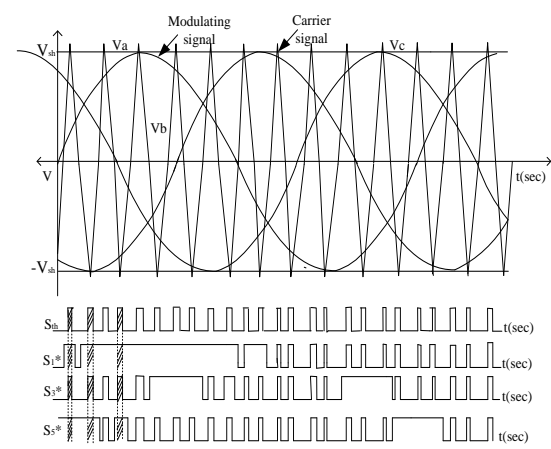

Fig 2: PWM Signals from Simple Boost control

In the figure 3 sinusoidal signal of each phase i.e. $\mathrm{mR}, \mathrm{mY}, \mathrm{mB}$ is compared with the high frequency carrier signal, the shoot-through obtained is then OR gate with the output of the pulse generator then we can obtain the modified signal in which shoot-through is injected.

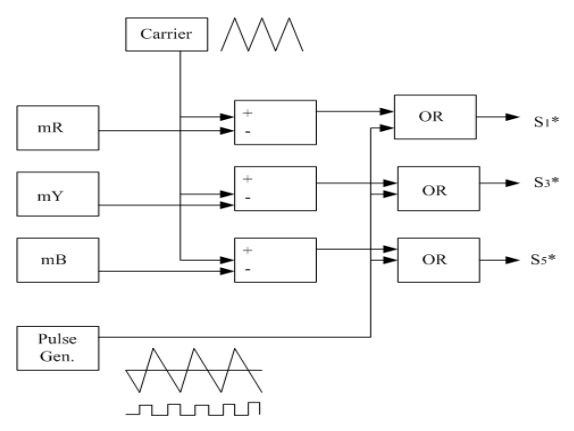

Fig 3: Implementation diagram of SBC

Mathematical expressions are: 
$D_{s h}=1-M$

$B=\frac{1}{1-2 \frac{T_{0}}{T}}=\frac{1}{1-2 D_{s h}}=\frac{1}{1-2(1-M)}$

$=\frac{1}{2 M-1}$

Where $\mathrm{G}$ is inverter voltage gain

$\mathrm{M}$ is modulation index

B is boost factor

$\mathrm{G}=\mathrm{M} \cdot \mathrm{B}=\frac{M}{2 M-1}$

The peak phase voltage of the Z-source inverter is given by

$V_{a c}=M \cdot B \frac{V_{i n}}{2}$

\section{Maximum Boost Control}

The disadvantage of Simple Boost Control (SBC) is overcome by introducing the Maximum Boost Control (MBC) method. In case of MBC the traditional zero state is totally converted into shoot-through state as a result the voltage stress across the switch is reduced compared to SBC[7][9].

The shoot-through states for MBC are generated by comparing the carrier signal with the maximum value and minimum value of modulating signals. So at any instant when the carrier signal is greater than the maximum value of modulating signal, shoot-through will generate. Similarly when the carrier signal is less than the minimum value of modulating signal, shoot-through will generate. The waveforms for switching pulses for MBC are shown in the figure 4.The advantages of this MBC PWM technique are that the output voltage is maximum as the boost factor is maximum. The disadvantage of this method is that during shoot-through states all switches will turns on so the switching loss is more.

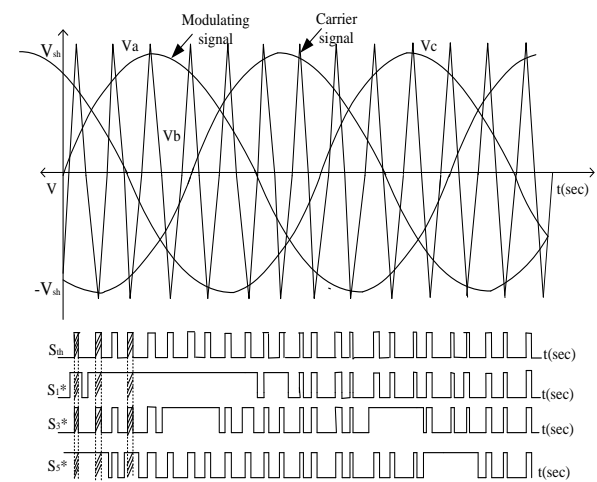

Fig 4: PWM Signals for Maximum Boost Control

Here in the figure 5 the sinusoidal signals from each phase are employed in a maximum block and a minimum block respectively. The maximum value of the signal as well as the minimum value of the signal output is then compared separately with the carrier to obtain the shoot-through states and is injected in between the switching pulses. 


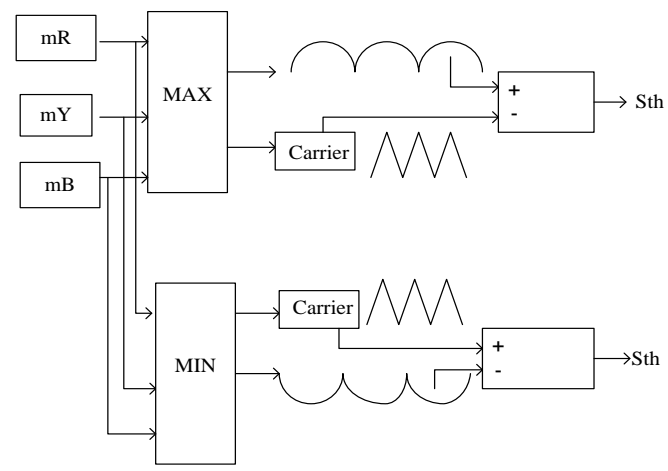

Fig 5: Implementation diagram of MBC

As can be seen from the figure 4, the circuit produces shoot through states when the triangular carrier wave is either greater than the maximum of the modulating signal. The shoot -through duty cycle varies each cycle. Now we have to evaluate the average shoot through duty cycle. The shoot through state repeats periodically every $\frac{\pi}{3}$.Now let us assume that the switching frequency is much higher than the modulation frequency, so for one switching period in the interval $\left(\frac{\pi}{6}, \frac{\pi}{2}\right)$, the shoot-through duty ratio can be expressed as following below

$\mathrm{V}_{\mathrm{i}}$ is the voltage fed to the inverter. Neglecting the switching frequency element, the average value of $\mathrm{V}_{\mathrm{i}}$ can be described as

$\mathrm{V}_{\mathrm{i}=}\left(1-\mathrm{D}_{0}\right) * \mathrm{BV}_{\mathrm{dc}}$

$\frac{T_{0}(\theta)}{T}=\frac{2-\left(M \sin \theta-M \sin \left(\theta-\frac{2 \pi}{3}\right)\right)}{2}$

The average shoot-through duty ratio can be calculated as by following equation

$\frac{\overline{T_{0}}}{T}=\frac{\int_{\frac{\pi}{6}}^{\frac{\pi}{2}} 2 d \theta-\left(\int_{\frac{\pi}{6}}^{\frac{\pi}{2}} M \sin \theta d \theta-\int_{\frac{\pi}{6}}^{\frac{\pi}{2}} M \sin \left(\theta-\frac{2 \pi}{3}\right) d \theta\right)}{\int_{\frac{\pi}{6}}^{\frac{\pi}{2}} 2 d \theta}$

$=\frac{2 \pi-3 \sqrt{3} M}{2 \pi}$

The boost factor B is obtained:

$B=\frac{1}{1-2 \frac{T_{0}}{T}}=\frac{\pi}{3 \sqrt{3} M-\pi}$

$\mathrm{D}_{0}$ has maximum value when $\theta=\frac{\pi}{3}$ and has minimum value $\theta=\frac{\pi}{6}$ or $\theta=\frac{\pi}{2} \quad \ldots$

\section{Maximum Boost Control with Third Harmonic Injection}

The operation principle is identical to the previous case; the only difference is that the modulating signal waveform is changed by third harmonic injection in figure 6 which is commonly use in three phase inverter system to increase the modulation index[7]. 

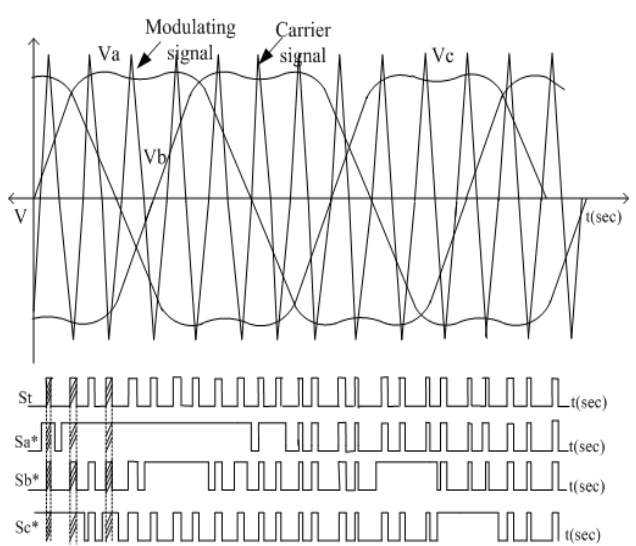

Fig 6: PWM signals for Maximum Boost Control with Third harmonic injection In this control, maximum modulation index $M=\frac{2}{\sqrt{3}}$ can be achieved at $\frac{1}{6}$ third harmonic injection to achieve $15 \%$ additional voltage for same dc bus voltage. Similar to the previous case, The shoot through state repeats periodically every $\frac{\pi}{3}$.Now let us assume that the switching frequency is much higher than the modulation frequency, so for one switching period in the interval $\left(\frac{\pi}{6}, \frac{\pi}{2}\right)$, the shoot-through duty ratio can be expressed as following

$\frac{T_{0}(\theta)}{T}=\frac{2-\left(M \sin \theta+\frac{1}{6} M \sin 3 \theta-\left(M \sin \left(\theta-\frac{2 \pi}{3}\right)+\frac{1}{6} M \sin 3 \theta\right)\right)}{2}$

The average shoot-through duty ratio can be calculated as by following equation

$\frac{T_{0}}{T}=\frac{\left.\left.\int_{\frac{\pi}{6}}^{\frac{\pi}{2}} 2 d \theta-\left(\int_{\frac{\pi}{6}}^{\frac{\pi}{2}} M \sin \theta+\frac{1}{6} M \sin 3 \theta\right) d \theta-\int_{\frac{\pi}{6}}^{\frac{\pi}{2}} M \sin \left(\theta-\frac{2 \pi}{3}\right)+\frac{1}{6} M \sin 3 \theta\right) d \theta\right)}{\int_{\frac{\pi}{6}}^{\frac{\pi}{2}} 2 d \theta}$

$=\frac{2 \pi-3 \sqrt{3} M}{2 \pi}$

The boost factor B is obtained:

$B=\frac{1}{1-2 \frac{T_{0}}{T}}=\frac{\pi}{3 \sqrt{3} M-\pi}$

$\mathrm{D}_{0}$ has maximum value when $\theta=\frac{\pi}{3}$ and has minimum value $\theta=\frac{\pi}{6}$ or $\theta=\frac{\pi}{2} \quad \ldots$

\section{Maximum Boost Control with Triplen Injection}

The operation principle is identical to the previous case; the only difference is that the modulating signal waveform is changed by triplen injection which is the new implementation in figure 7. In this control, maximum modulation index $\mathrm{M}=\frac{2}{\sqrt{3}}$ can be achieved by triplen injection is a common mode signal denoted as $\mathrm{CM}$. 


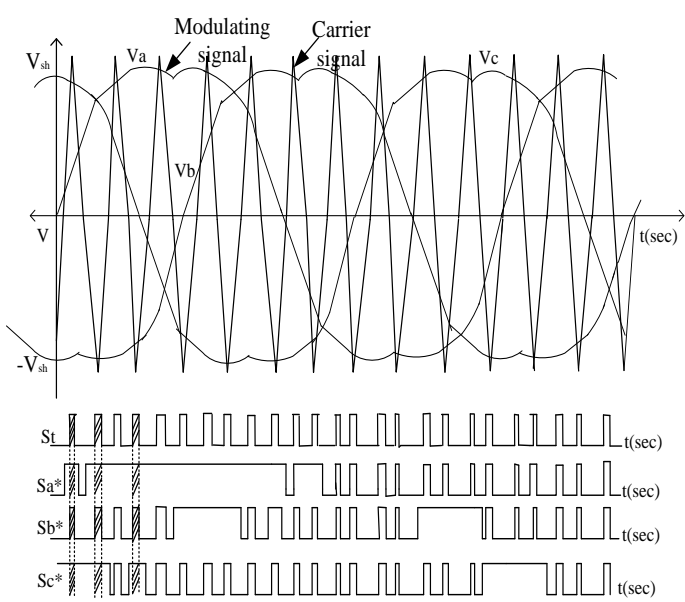

Fig 7: PWM Signals for Maximum Boost Control with Triplen injection

Similar to the previous case, the shoot through state repeats periodically every $\frac{\pi}{3}$. Now let us assume that the switching frequency is much higher than the modulation frequency, so for one switching period in the interval $\left(\frac{\pi}{6}, \frac{\pi}{2}\right)$, the shoot-through duty ratio can be expressed as following below

$\frac{T_{0}(\theta)}{T}=\frac{2-\left(M \sin \theta+C M-\left(M \sin \left(\theta-\frac{2 \pi}{3}\right)+C M\right)\right)}{2}$

The average shoot-through duty ratio can be calculated as by following equation

$\frac{-}{T}=\frac{\left.\left.\int_{\frac{\pi}{6}}^{\frac{\pi}{2}} 2 d \theta-\left(\int_{\frac{\pi}{6}}^{\frac{\pi}{2}} M \sin \theta+C M\right) d \theta-\int_{\frac{\pi}{6}}^{\frac{\pi}{2}} M \sin \left(\theta-\frac{2 \pi}{3}\right)+C M\right) d \theta\right)}{\int_{\frac{\pi}{6}}^{\frac{\pi}{2}} 2 d \theta}$

$=\frac{2 \pi-3 \sqrt{3} M}{2 \pi}$

The boost factor B is obtaned:

$B=\frac{1}{1-2 \frac{T_{0}}{T}}=\frac{\pi}{3 \sqrt{3} M-\pi}$

$\mathrm{D}_{0}$ has maximum value when $\theta=\frac{\pi}{3}$ and has minimum value $\theta=\frac{\pi}{6}$ or $\theta=\frac{\pi}{2} \quad \ldots$

VII. Simulation results and tables:

The Z-source inverter is modeled using MATLAB. The simulation is done by considering the following conditions:

DC bus voltage, $\mathrm{VDC}=162 \mathrm{~V}$, Modulation index, $\mathrm{m}=0.642$, Nominal frequency $=50 \mathrm{~Hz}$, Switching frequency fsw $=10 \mathrm{KHz}$, Resistance $(\mathrm{R})=1 \mathrm{ohm}$,Inductance $(\mathrm{L})=160 \mathrm{uH}$, Capacitance $=1000 \mathrm{uF}$.

The below table 1 is depicted on the basis of simulation results we obtained and it is clearly evident that Maximum boost control is much better than Simple boost as peak current and peak voltage is more in Maximum boost control for the same modulation index, same switching frequency . From the below simulation waveforms fig $8(\mathrm{a}), 8(\mathrm{~b}), 8(\mathrm{c}), 8(\mathrm{~d})$ its is seen that dc voltage across capacitor is increasing in Maximum Boost 
control ,Maximum Boost control with triplen injection maximum boost control and maximum boost with third harmonic injection and other methods compared to simple boost ,so Maximum boost and other injection methods are better.

The below table 2 is depicted on the basis of simulation results we obtained and it is clearly seen that maximum boost control with triplen injection is much better than maximum boost control and maximum boost with third harmonic injection as in maximum boost control with triplen injection the load current ripple, inductor current ripple as well as capacitor voltage ripple is much less as modulation index increases for same switching frequency as shown on fig $8(\mathrm{e}), 8(\mathrm{f}) .8(\mathrm{~g})$..

Table 1

Comparison study Of SBC and $\mathrm{MBC}, \mathrm{fsw}=10 \mathrm{KHz} \quad \mathrm{V}_{\mathrm{dc}}=162 \mathrm{v}$

\begin{tabular}{|c|c|c|c|c|}
\hline $\begin{array}{c}\text { Modulati } \\
\text { on index }\end{array}$ & \multicolumn{2}{|c|}{ Simple Boost Control } & \multicolumn{2}{c|}{ Maximum Boost Control } \\
\hline & $V_{\text {peak(rms) }}$ & Peak current(A) & $V_{\text {peak(rms) }}$ Peak current(A) \\
\hline 0.642 & 118.36 & 5.71 & 148.4 & 8.8 \\
\hline 0.65 & 114.4 & 5.53 & 164.1 & 8.48 \\
\hline 0.66 & 110.02 & 5.32 & 176.2 & 8 \\
\hline 0.67 & 105.7 & 5.12 & 181.8 & 8.1 \\
\hline 0.69 & 98.64 & 4.78 & 180.3 & 7.5 \\
\hline 0.7 & 95.45 & 4.61 & 176.2 & 7.15 \\
\hline 0.8 & 74.45 & 3.6 & 127.8 & 6.6 \\
\hline
\end{tabular}

TABLE 2

Comparison study Of MBC and its implementation, $\mathrm{fsw}=10 \mathrm{KHz} \quad \mathrm{Vdc}=162 \mathrm{v}$

\begin{tabular}{|l|c|c|c|c|c|c|c|c|c|}
\hline $\begin{array}{c}\text { Modulat } \\
\text { ion } \\
\text { index }\end{array}$ & \multicolumn{2}{|c|}{$\begin{array}{c}\text { Maximum Boost } \\
\text { control(MBC) }\end{array}$} & \multicolumn{2}{c|}{$\begin{array}{c}\text { MBC with triplen } \\
\text { injection }\end{array}$} & \multicolumn{3}{|c|}{$\begin{array}{c}\text { MBC with third } \\
\text { harmonic injection }\end{array}$} \\
\hline Load current & $\begin{array}{c}\text { Inductor } \\
\text { current } \\
\text { ripple(A)(A) }\end{array}$ & $\begin{array}{c}\text { Capacitor } \\
\text { voltage } \\
\text { ripple(V) }\end{array}$ & $\begin{array}{c}\text { Load current } \\
\text { ripple(A) }\end{array}$ & $\begin{array}{c}\text { Inductor } \\
\text { current } \\
\text { ripple(A) }\end{array}$ & $\begin{array}{c}\text { Capacitor } \\
\text { voltage } \\
\text { ripple(V) }\end{array}$ & $\begin{array}{c}\text { Load current } \\
\text { ripple(A) }\end{array}$ & $\begin{array}{c}\text { Inductor } \\
\text { current } \\
\text { ripple(A) }\end{array}$ & $\begin{array}{c}\text { Capacitor } \\
\text { voltage } \\
\text { ripple(V) }\end{array}$ \\
\hline 0.642 & 0.15 & 0.2 & 5.5 & 0.12 & 0.2 & 5 & 0.12 & 0.2 & 5 \\
\hline 0.65 & 0.13 & 0.2 & 5 & 0.1 & 0.2 & 5 & 0.11 & 0.2 & 5 \\
\hline 0.66 & 0.1 & 0.2 & 4.5 & 0.1 & 0.18 & 4 & 0.1 & 0.2 & 4 \\
\hline 0.67 & 0.1 & 0.2 & 3 & 0.1 & 0.16 & 3 & 0.1 & 0.2 & 3.5 \\
\hline 0.69 & 0.1 & 0.2 & 2.5 & 0.1 & 0.15 & 2 & 0.1 & 0.2 & 2.5 \\
\hline 0.7 & 0.1 & 0.18 & 3 & 0.1 & 0.14 & 2 & 0.1 & 0.15 & 2 \\
\hline 0.8 & 0.06 & 0.15 & 1.2 & 0.07 & 0.01 & 1 & 0.07 & 0.14 & 2 \\
\hline
\end{tabular}


Fig8(a)Voltage across capacitor for Simple Boost Control $\quad V_{d c}=162 v \quad m=0.642$

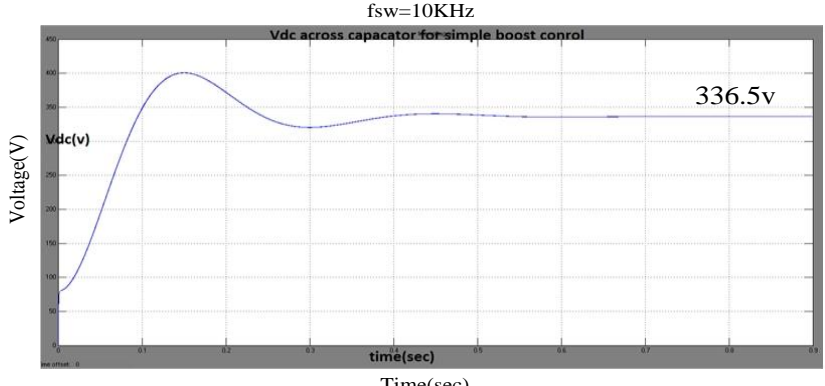

Time $(\mathrm{sec})$

Fig 8(b)Voltage across capacitor for Maximum Boost Control $\quad V_{\mathrm{dc}}=162 \mathrm{v}$ $\mathrm{m}=0.642 \quad \mathrm{fsw}=10 \mathrm{KHz}$

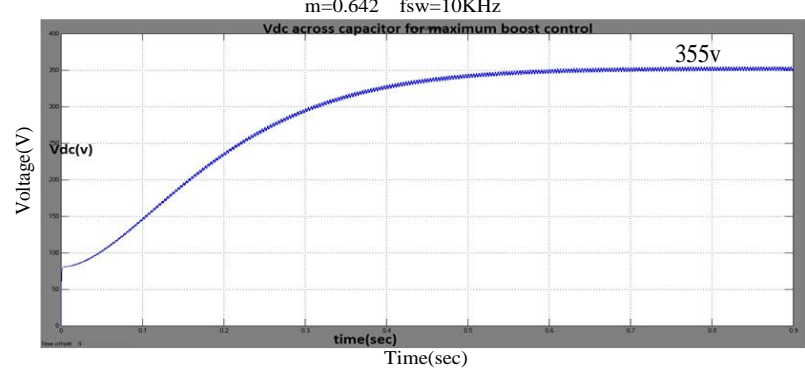

Time $(\mathrm{sec})$

Fig 8(c)Capacitor voltage for Maximum Boost Control with third harmonic injection $\quad V_{\mathrm{dc}}=162 \mathrm{v} \mathrm{m}=0.642 \quad \mathrm{fsw}=10 \mathrm{KHz}$

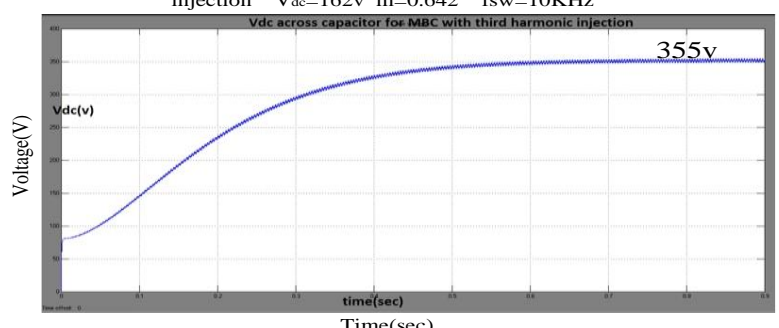
$\mathrm{V}_{\mathrm{dc}}=162 \mathrm{v} \quad \mathrm{m}=0.642 \quad \mathrm{fsw}=10 \mathrm{KHz}$

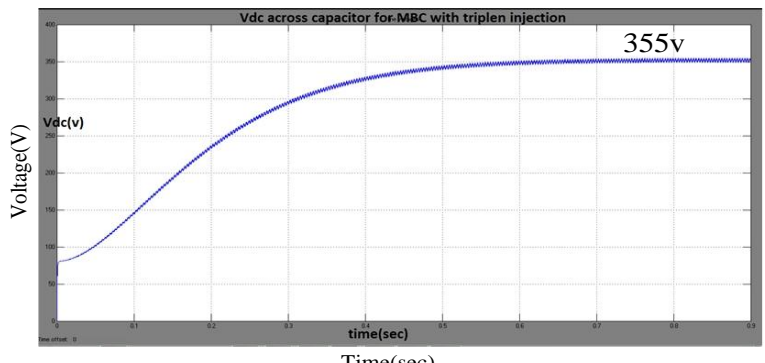

Time $(\mathrm{sec})$

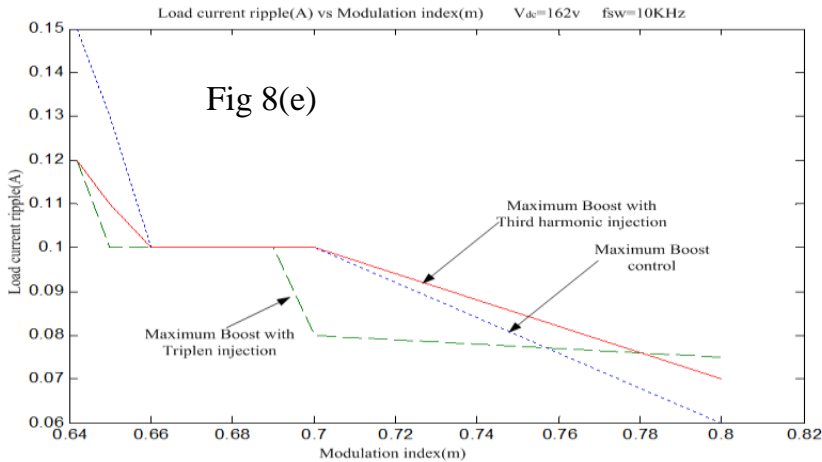



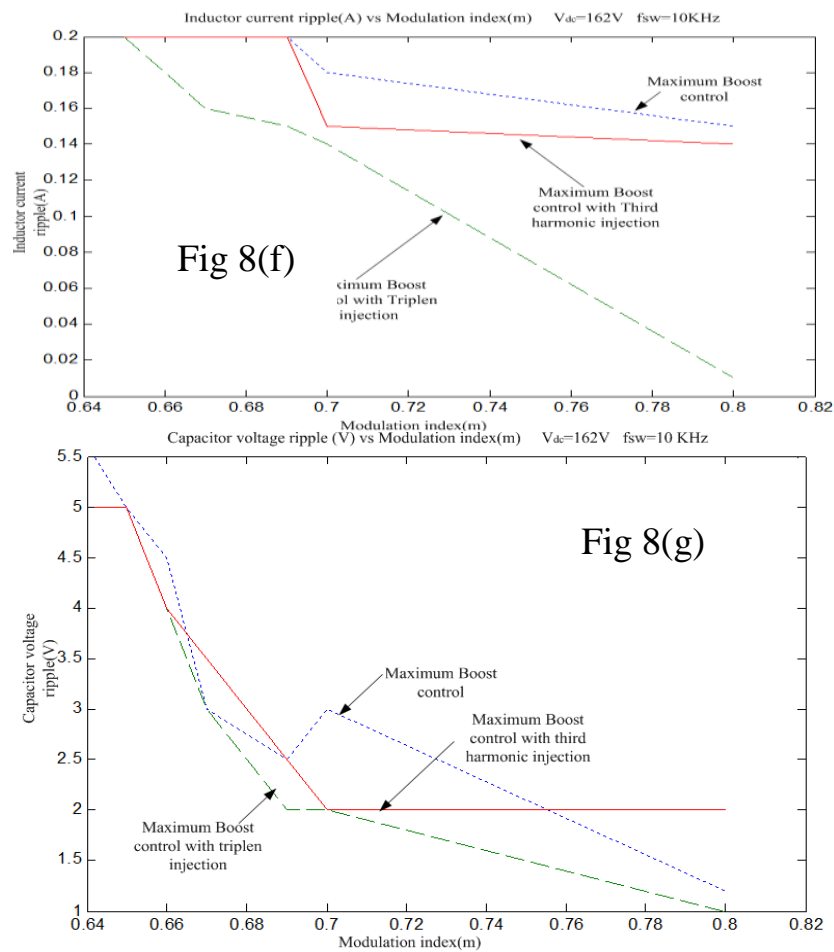

\section{Conclusions}

In this chapter we discussed about different PWM techniques that are used to control Z-source inverter. The SBC control method, MBC control method as well as its implementation with triplen injection \& Third harmonic injection and the simulation results showed that the $\mathrm{MBC}$ with triplen injection is much more better than the other as the voltage across capacitor is increasing and current ripple is much less in this method compared for same modulation index and same switching frequency has been discussed in detailed.

\section{References:}

[1]. N. Mohan, W. P. Robbin, and T. Undeland, Power Electronics: Converters, Applications, and Design, 2nd ed. New York: Wiley, 1995.

[2]. $\quad$ F. Z. Peng, "Z-source inverter", IEEE Transactions on Industry Applications, vol. 39, pp. 504-510, Mar-Apr 2003.

[3]. P.C. Loh, D.M. Vilathgamuwa, Y.S. Lai, G.T. Chua, and Y. Li, "Pulse-Width Modulation of Z-Source Inverter", in Conf. Rec. 2004 IEEE Industry Applications Conferences, pp. 148-155.

[4]. J. B. Liu, J. G. Hu, and L. Y Xu, "A modified space vector PWM for Z-source inverter - Modeling and design," ICEMS 2005, in Proceedings of the Eighth International Conference on Electrical Machines and Systems, Vols 1-3, pp. 1242-1247, 2005.

[5]. N. Muntean, L. Tutelea, and I. Boldea, "A Modified Carrier-Based PWM Modulation Technique in Z-Source Inverter", in 2007 Int. Aegean Conf. on Electrical Machines and Power Electronics, pp. 174180

[6]. Q.V. Tran, T.W. Chun, J.R. Ahn, and H.H. Lee, "Algorithms for Controlling Both the DC Boost and AC Output Voltage of ZSource Inverter", IEEE Transactions on Industrial Electronics, vol. 54, no. 5, October 2007.

[7]. F. Z. Peng and Miaosen Shen, Zhaoming Qian, "Maximum Boost Control of the Z-source Inverter," in Proc. of IEEE PESC 2004.

[8]. L. Poh Chiang, D. M. Vilathgamuwa, Y. S. Lai, C. Geok Tin, and Y. Li, "Pulse-width modulation of Z-source inverters,"IEEE Transactions on Power Electronics, vol. 20, pp. 1346-1355, 2005.

[9]. B.Y. Husodo, M. Anwari, and S.M. Ayob, "Analysis and Simulations of Z-Source Inverter Control Methods", IEEE Transactions on Industry Applications, vol. 42, pp. 770 - 778, May-Jun 2006.

[10]. J. Li, J. Liu, and Z. Liu, "Loss Oriented Evaluation and Comparison of Z-Source Inverters Using Different Pulse Width Modulation Strategies", in 2009 IEEE Applied Power Electronics Conference and Exposition. 